\title{
How flexperts deal with changing expertise demands: A qualitative study into the processes of expertise renewal
}

\author{
Lonneke S. Frie ${ }^{1,2}$ (1) | Karin C. J. M. Potting ${ }^{1}$ | Ellen Sjoer ${ }^{3}$ | \\ Beatrice I. J. M. Van der Heijden ${ }^{2,4,5,6}$ | Hubert P. L. M. Korzilius ${ }^{2}$
}

\author{
${ }^{1}$ Research Group Sustainable Talent \\ Development and Faculty M\&O/Study \\ Program HRM, The Hague University of \\ Applied Sciences, The Hague, the Netherlands \\ ${ }^{2}$ Institute for Management Research, Radboud \\ University, Nijmegen, the Netherlands \\ ${ }^{3}$ Research Group Sustainable Talent \\ Development, The Hague University of \\ Applied Sciences, The Hague, the Netherlands \\ ${ }^{4}$ Open University of the Netherlands, Heerlen, \\ the Netherlands \\ ${ }^{5}$ Kingston University, London, UK \\ ${ }^{6}$ Hubei University, Wuhan, China

\section{Correspondence} \\ Lonneke Frie, The Hague University of Applied \\ Sciences, Research Group Sustainable Talent \\ Development \& Faculty M\&O/Study Program \\ HRM, P.O. Box 13336, $2501 \mathrm{EH}$ The Hague, \\ the Netherlands. \\ Email: I.frie@hhs.nl
}

Flexperts are a particular category of experts who are in the possession of in-depth domain-specific knowledge and skills combined with the ability to develop and materialize new areas of expertise, that is, expertise renewal. This ability enables them to decisively respond to new expertise demands that arise as a result of changes in their expertise territories. Thus far, there is a limited understanding of how flexperts develop new areas of expertise in a complex, professional setting, and how they accomplish to materialize this new expertise for multiple stakeholders, both inside and outside organizations. In this qualitative interview study, we aim to increase our understanding of the processes by which flexperts accomplish the renewal of their expertise. Ten Dutch flexperts, known for their high level of expert performance and ability to renew their expertise, and from a variety of disciplines, were interviewed. Based on the findings of our study, we have developed a model that summarizes their expertise renewal processes. This Model of Expertise Renewal extends process models on expertise redevelopment and adaptive expertise, and provides directions for future research on how the ability of expertise renewal contributes to the career sustainability of experts. Furthermore, it provides experts, Human Resource Development (HRD) practitioners, and line managers with a framework for creating learning paths and interventions for renewing expertise in case expertise territories are about to change.

\section{KEYWORDS}

career sustainability, flexpertise, Model of Expertise Renewal, qualitative research 


\section{1 | INTRODUCTION: CHANGING EXPERTISE DEMANDS IN NOWADAYS' WORKING LIFE}

Adequately responding to new expertise demands is perceived to be an important capability for professionals in nowadays' working life to safeguard the sustainability of their careers (Susskind \& Susskind, 2015; Van der Heijden \& De Vos, 2015). Grenier and Kehrhahn (2008) stated that professionals frequently experience a need to "redevelop" their expertise as a result of changes in their so-called "expertise territories" wherein their knowledge and skills come into play. In particular, they distinguished three types of expertise territories where the necessity for the redevelopment of expertise is prevalent. First, the redevelopment of expertise can be required as a result of changes in its content, which relates to the knowledge and skills that define or delineate a certain expertise domain. Over the past few decades, the content of expertise domains appeared to become obsolete sooner than ever before (Van der Heijden, 2005). This is partly due to an increasingly shorter half-life of knowledge (Arbesman, 2012), which is defined as the time it takes to become half as knowledgeable in a field without any new learning (Neimeyer, Taylor, Rozensky, \& Cox, 2014, p. 92). Expertise can in particular become obsolete or less demanded if new technology (partly) replaces the knowledge and skills that are key to excel in a certain expertise domain (McKinsey, 2017). These developments imply that in nowadays' working life higher levels of domain-specific knowledge and skills are required (Will-Zocholl, 2017; World Economic Forum, 2016; World Employment Confederation, 2016), and/or the development of new knowledge and skills (Levy \& Murnane, 2004; OECD, 2009). Second, changes in the environment, referring to the setting in which professionals apply their expertise, also urge the need for redevelopment. When environmental elements change, such as an organization's culture, procedures or systems, strategies by which professionals materialize their expertise might need to be adjusted or even replaced by new ones. Currently, professionals are said to encounter these changes more frequently due to the effects of digitalization, robotization, and globalization (Laloux, 2015). Third, changing expertise demands also stem from changes in the constituency, that is, the audience that is interested in the specific expertise. After all, professionals need to have an audience that recognizes and actually labels their knowledge and skills as expertise (Grenier \& Kehrhahn, 2008, p. 210). The latter pertains to the function others ascribe to expertise, as reflected by expert reputation and the related willingness of an audience to pay for the specific expertise (Mieg, 2006). Thus, when the audience changes, which could be the result of changes in the expertise domain and/or in the environment, professionals need to (re)build their expert reputation among (new) groups of stakeholders.

However, meeting these changing expertise demands at the current labor market is by no means an easy task (Van der Heijden, 2005) and not necessarily mastered by each professional (e.g., CBS, 2015). Van der Heijden (1998) coined the term flexperts for those experts who have the ability to meet changing expertise requirements above and beyond their already existing in-depth domain-specific knowledge and skills. This study aims to increase our understanding of what this ability, which we call "expertise renewal," entails by answering the following research question: By which processes do flexperts accomplish to renew their expertise? For the purpose of this qualitative interview study, we define processes as the range of activities that flexperts undertake in interaction with their expertise territories to develop and materialize a new area of expertise that might be beneficial for multiple stakeholders. The following review of theories and empirical studies on the nature, development, and materialization of expertise is meant to reveal lacunas in the Human Resource Development (HRD) scholarly knowledge on expertise renewal in a complex, professional context.

\section{1 | The nature of expertise}

During the past few decades, a large amount of research on the nature of expertise has been conducted, by comparing the performance of experts with their less-experienced peers or novices. This research has typically been done within expertise domains that are characterized by a relatively stable and well-delineated knowledge base and by a domain-specific skill set, such as chess, mathematics, and sports (Feltovich, Prietula, \& Ericsson, 2018). However, there has been less focus on studying the nature of expertise in complex, professional contexts in which the multiplicity and changeability of domains prevail (Grenier \& Kehrhahn, 2008, p. 204), and that are characteristics for 
upcoming expertise areas in, for example, the professional fields of Information and Communication Technology (ICT) and HRD.

Based on an elaborate literature review and extensive empirical work on the performance of experts in professional settings, Van der Heijden $(1998,2000)^{1}$ came up with a comprehensive definition and multidimensional operationalization of the concept of occupational expertise. The first dimension concerns the acknowledgement that professionals need to have a vast amount of relevant domain-specific knowledge, often described as declarative or factual knowledge ("knowing that"), procedural knowledge ("knowing how"), and conditional knowledge ("knowing when and where or under what conditions") (see also Alexander, Schallert, \& Hare, 1991). The second dimension, so-called meta-cognitive skills, refers to selfconsciousness about strengths and weaknesses in one's own performance domain, and insights about how to compensate for the specific lacking knowledge and/or skills. The third dimension of occupational expertise relates to the domainspecific skills that enable a professional to translate his/her knowledge into overt behavior, and to deliver high-quality work. These three dimensions taken together reflect the degree by which individuals master the aforementioned content of an expertise domain and are able to evaluate if their own knowledge and skills fit the environment in which these have to be materialized. The fourth dimension of expertise concerns the social recognition from relevant stakeholders, both within and outside one's working organization, with regard to the professional's achievements. This aspect relates to the capability to (re)build an expert reputation (Germain \& Tejeda, 2012), which might be required when changes in the aforementioned constituency of an expertise domain occur. The fifth expertise dimension, growth and flexibility, refers to the fact that professionals need to develop knowledge and skills in new or adjacent areas of expertise in response to changes in the earlier mentioned three expertise territories. A high score on this dimension is interpreted to be indicative for the performance of flexperts. Van der Heijden (2000) defined "flexperts" as "individuals who are capable of acquiring more than one area of expertise within adjacent or radically different fields or who are capable of acquiring a strategy to master a new area of expertise or expert performance in another territory" (p. 12). As suggested by Van der Heijden (2000, p. 30), more insights into concrete examples of expert performances and behaviors might increase our understanding of what constitutes expertise, including the dimension of growth and flexibility.

Recently, different researchers showed a regaining interest in better understanding what is needed for meeting the changing demands for expertise, which Van der Heijden $(1998,2000)$ labelled as "flexpertise". Birney, Beckmann, and Wood (2012) used the term "flexible expertise" for "the capacity to move across different domains and problem types smoothly and appropriately" (p. 573). Based on their study of the precursors of flexible expertise, they argued that flexible expertise differs qualitatively from routine expertise. Their distinction between these two types of expertise resembles the difference between adaptive expertise and routine expertise as originally introduced by Hatano and Inagaki (1986). With regard to the first distinguished form of expertise, Hatano and Oura (2003) stated that experts who have adaptive expertise "can be characterized by their flexible, innovative, and creative competencies within the domain" (p. 28), building upon their routine, more mechanical, rule-based, expertise. In a similar vein, based on a thorough literature review on individual and environmental factors influencing adaptive expertise, Bohle Carbonell, Stalmeier, Könings, Segers, and Van Merriënboer (2014) defined adaptive expertise as "the ability to use existing expertise in a new context in which the task, method or desired outcome is not known in advance" (p. 15). As such, it allows for the easy overcoming of the novelty of a certain setting in which the expertise has to be applied, and to quickly build up expert level performance. Their descriptions of novel contexts or settings seem to relate to changes in the aforementioned expertise environment. The authors concluded that both the main ingredients and the development of adaptive expertise are not yet well understood. Therefore, to further our scholarly understanding of what makes professionals develop adaptive expertise, Bohle Carbonell, Könings, Segers, and Van Merriënboer (2016) called for interview studies on the strategies that experts apply to deal with novel contexts.

\section{2 | The continuous development and materialization of expertise}

Previous scholarly work on the flexible or adaptive nature of expertise implies that being an expert is not a final state, but requires the continuous development of expertise. However, most empirical research on expertise 
development has focused on how individuals go through different stages to become an expert (see Ericsson, 2014 for a summary of influential models). In particular, we lack insight into how a professional career unfolds when expertise territories change and experts need to continuously renew their expertise in favor of the sustainability of their career (De Vos \& Van der Heijden, 2017).

Grenier and Kehrhahn (2008) defined a three-stage process model for "expertise redevelopment." The first stage refers to dependence in which the expert needs to rely on other people and resources, and learns to adapt his/her current repertoire to new demands. During the second stage of independence, there is an increasing comfort with the new knowledge, skills and/or role, that allows experts to supplement their existing knowledge base with new information. In the third and final stage of the so-called transcendence, the expert has developed a sense of ownership regarding the new expertise by which the latter becomes more tacit, and which is accompanied by a growing confidence to experiment. A limitation of the model by Grenier and Kehrhahn (2008) is that it leaves relatively unanswered what triggers redevelopment in the context of a wide variety of changes in expertise territories, how experts accomplish the move from one stage to the other in interaction with elements of their environment, and how their new expertise materializes or manifests itself to different audiences. These latter aspects are partly addressed by Ward, Gore, Hutton, Conway, and Hoffman (2018) who conducted a review of research on adaptive skills. They concluded that "adaptive skills is the condition sine qua non of expertise" (p. 46), meaning that being an expert entails being adaptable (i.e., as was addressed by the growth and flexibility dimension of expertise of Van der Heijden, 2000). They argued that it is important to distinguish between what constitutes expertise (i.e., the nature of expertise), and how professionals use this expertise to make effective contributions in those contexts where these matter most. Accordingly, Ward et al. (2018) formulated a conceptual "macrocognitive model of adaptive skill" for future empirical research needs incorporating HRD practices that are necessary in this regard. More specifically, this model consists of a process of sense-making where experts elaborate, question, and reframe their understanding of a certain situation. As such, this process coincides with a cycle of flexecution by which individuals pursue goals in a complex setting wherein they encounter emergent and unpredictable challenges in their professional field. The authors label this process as adaptive performance, that is, performance by discovery, as learning takes place by the doing.

A limitation of the models by Grenier and Kehrhahn (2008) and by Ward et al. (2018) is that none of them addresses how individual expertise materializes at multiple levels of an organization. In the light of this, Marand and Noe (2017) identified an increasing need for understanding the emergent, bottom-up processes through which individual expertise translates itself into valuable organizational outcomes in interaction with a complex setting. In their view, HRD plays an important role by providing the necessary conditions and processes for this materialization. However, in the light of the shift toward more sustainable business models, Thunnissen, Boselie, and Fruytier (2013) argued that HRD practitioners should not only focus on the desired outcomes for an organization. Rather, they should take their practice a step further by helping individuals to create (non)economical value beyond the boundaries of an organization, hereby incorporating the needs of multiple stakeholders both inside and outside an organization. This broader constituency urges professionals to increasingly focus on how they are known, by whom and for what, rather than merely on what they should know (Holtskog, 2017; Oldham \& Hackman, 2010).

To summarize, in the context of changing expertise territories in nowadays' working life, scholarly researchers on the nature, development, and materialization of expertise had previously called for a better understanding of how professionals, flexperts in particular, continuously develop expertise in adjacent or new expertise domains. In addition, they stressed the need for more insight into how these flexperts materialize their newly required knowledge and skills for multiple stakeholders both inside and outside an organization, and, finally, how meeting the demands for new expertise contributes to the sustainability of an individual career. 


\section{2 | METHOD}

To contribute to the HRD literature, we adopted a qualitative interview study to conduct an initial exploration of the processes by which flexperts continuously renew their expertise, in specific, aimed at better understanding how they develop and materialize new expertise throughout their career.

\section{1 | Sample}

Prior to a purposeful selection of flexperts, we defined five criteria, which should all be met, that strive for a representative sample covering a maximum variation of expertise renewal episodes (Boeije, 2010, p. 36). We derived these criteria from the expertise theories and current labor market demands as described in the introduction section. First, in line with Van der Heijden (1998, 2000), we intended to build upon a general theory of expertise and recruited flexperts from a variety of occupational disciplines. Second, we selected highly educated flexperts given the everincreasing levels of knowledge and skills that are required (e.g., Levy \& Murnane, 2004; Will-Zocholl, 2017). Third, following the seminal finding that around $10,000 \mathrm{hr}$ of deliberate study and practice are required to perform at the expert level (Chi, Glaser, \& Farr, 1988; Ericsson, Krampe, \& Tesch-Römer, 1993; Simon \& Chase, 1973), we needed to sample professionals with ample experience. In addition, we gave account of studies that provide valid criticism to the 10,000 hr rule. For example, the review study by Macnamara, Hambrick, and Oswald (2014) showed that most variance in performance between experts and novices could not be explained by differences in deliberate practice. We also acknowledged that in new areas of expertise, professionals can reach "world-class levels" in fewer than 10 years given a lack of history in the field (Ericsson, 2006, p. 690). Nevertheless, we decided to select flexperts who had at least 10 years of experience in their specific field after graduation to have sufficient expertise renewal episodes to reflect upon. Fourth, to address the issue of required reputation, the flexperts in our sample needed to have been recognized as high-performing and renewing experts by representatives from at least two of the following stakeholder groups: the community of peers in their field, users of their specific expertise within their own organization, and the general public. With regard to the first stakeholder perspective, the flexperts should have received two or more awards or official acknowledgements for innovative or renewing contributions to a certain field of expertise. From the organizational perspective, the flexperts should have been assessed by their supervisor and/or talent manager as a high-performing expert who was capable of materializing new areas of expertise for the organization, as part of a performance appraisal during the preceding 3 years. From the point of view of the general public, we aimed to select renowned flexperts who were consulted or put in the spotlight for their contributions to, or for renewing perspectives on, societal challenges in the public media, that is to say journals, television programs, social media, and/or radio. And finally, the flexperts in our sample should have developed and materialized at least two new expertise areas throughout their career. By applying this selection criterion, we intended to be sure that the expertise renewal was not a mere coincidence but an ability that could be applied more than once. We earmarked the developed expertise as "new" in case the specific stakeholders stated this expertise to be new in relation to their domain.

\section{2 | Procedure}

We contacted flexperts who met all of the sampling criteria using a snowball sampling procedure through the networks of the first two authors of this article, in parallel to conducting the interviews. In particular, we approached six companies, out of which three of their talent managers responded with a list of five flexperts in total. Four of them responded and decided to participate in our study. In parallel, we addressed seven public experts directly, out of whom six responded and decided to participate.

The primary method of data collection involved retrospective, semistructured interviews, which is a commonly used method to recollect the long-term process of expertise development (Sosniak, 2006). The first two authors conducted the interviews using a set of open questions to produce rich, descriptive data on expertise renewal processes. 
To begin with, flexperts were asked to describe the succession of expertise areas they had developed throughout their career. In a dialogue with the flexpert, we selected one episode in which a new area of expertise was developed and materialized. Next, we went into the elements that had stimulated and hindered them, into concrete examples of the latter, and into what triggered the participating flexperts to look for the development and materialization of a new area of expertise. In addition, we dealt with similarities and dissimilarities with other expertise renewal episodes in the flexpert's career. We prompted the recollection of information by probing questions such as: What did you do? What did you do next? What was the effect? As part of the selection process, and in parallel to conducting the interviews and their coding (see section Data Analysis), the first two authors consulted supplementary data from online resources and public media on the flexperts' broadcasting strategies, (co)developed products, and reputation/ recognitions of their achievements from the general public and from peers, to elaborate our understanding of their renewal episodes. Directly after each interview, both interviewers independently wrote down their first impressions from the interview and cross checked their notes to align on which emerging processes might require further elaboration in successive interviews. After five interviews, we constructed a tentative conceptualization of possible processes. After ten interviews, we appeared to have reached the point of saturation (Anderson, 2017, p. 129) given the identification of similar renewal processes across interviewees, expertise areas, and organization types, while, at the same time, having managed to collect a rich variety of behavioral examples of these processes. We decided to collect additional information on how flexperts differ from less-flexible experts and, if needed, more information as well on process features, sequences, and their interrelationships, during a process of member validation with half of the interviewees (see section Data Analysis).

The final sample consisted of ten renowned Dutch flexperts (six men and four women) who developed new areas of expertise in the following broad fields ${ }^{2}$ : $H R D(R 1,5)$, Medical (R2, 7, 9), Business Management (R3), ICT (R4, 8, 10), and Education (R6). Their experience ranged from 8 to 30 years (on average 21 years) in a wide variety of organizational types (e.g., multinational, university, freelance network, hospital, and consultancy firm). All interviews were conducted from May until July 2016 and lasted 59 min on average (ranging from 46 to 80). All flexperts provided consent for both recording the interviews and the member validation (see section Data Analysis). A third party agency made full verbatim transcripts of all interviews. The resulting transcripts were uploaded in ATLAS.ti (version 7) for data analysis.

\section{3 | Data analysis}

As the process by which flexperts renew their expertise is a relatively unknown phenomenon and given that prior empirical studies in this field are limited, we used an inductive approach for an in-depth analysis of the interview transcripts. This analysis was meant to make an initial exploration of the processes by which flexperts renew their expertise throughout their career, and what they considered as stimulating and hindering elements. In particular, we used open, axial, and theoretical coding for inducing an expertise renewal model (Boeije, 2010) and applied Charmaz's (2014) guidelines for coding actions undertaken.

For the process of open coding, the first two authors created codes consisting of short names that were "grounded" in the interview data and that reflected actions and their stimulating or hindering elements. We used the same code for text segments wherein interviewees used highly similar wording. Moreover, we used "in vivo" codes to capture the flexperts' terminology (Strauss \& Corbin, 2007) to facilitate retrieval of this information for the successive coding steps and reporting. Next, we started the process of axial coding by comparing, discussing, and clustering codes to uncover the processes by which flexperts interacted with their expertise territories, the stimulating and hindering elements for these processes, and their outcomes (Strauss \& Corbin, 2007). Throughout this process of iterative clustering, we checked for similarities and dissimilarities among codes and (sub)clusters of codes by verifying text segments within and across interview transcripts, and we changed the initial coding where necessary. In addition, during the processes of interviewing and coding, we kept track of our reflective thoughts and decisions by means of memo writing (Boeije, 2010, p. 70). To secure the consistency and quality of our coding (Murphy, Klotz, \& 
Kreiner, 2017), the first two authors jointly distinguished text fragments and assigned open codes to them. Next, the first author created axial codes during several iterations in which the second author reviewed the clustering. Disagreements among the two coders were solved by thorough discussions after verifying the original interview transcripts. Subsequently, we started the process of theoretical coding to develop a conceptual model for processes of expertise renewal. This resulted in the emergence of alternative conceptual models and accompanying theoretical concepts based upon a thorough brainstorm about the key processes, and the essence of the relationships between these, that were, subsequently verified using the interview data. The resulting model was then compared with the aforementioned theories on the nature, development, and materialization of expertise, and with additional scholarly literature on the processes of expertise renewal that we derived from the coding process (see Discussion section for more details).

A member validation (Anderson, 2017, p. 129; Boeije, 2010, p. 177) was carried out with half of the flexperts between June and August 2017 to verify the credibility of our analyses. With each flexpert individually, we reflected upon their individual expertise renewal processes which we derived from analyzing their interview transcripts and supplementary data. In addition, we cross validated the emerging process model (Murphy et al., 2017, p. 302) to determine to what extent the flexperts endorsed the visualization of the process model, the distinguished processes and their relationships, and whether there were missing elements (Andersen et al., 2010). In addition, we asked in what way the flexperts considered themselves to be different from experts who they perceived as less capable of renewing their expertise.

\section{3 | FINDINGS}

Figure $1^{3}$ summarizes the outcomes of our coding processes. It shows the first-order codes as a result of open coding, the more abstract categories that we derived from the axial coding, and the aggregated theoretical dimensions that finally led to the formulation of our newly developed conceptual model.

Later, we describe in more detail how and why each process was applied by the flexperts, and which elements they considered to have stimulated or hindered these processes. Words between double brackets capture the wording used by the flexperts. Next, we discuss the conceptual Model of Expertise Renewal that we have derived from our analysis.

\section{1 | Generating ideas: An important source of expertise renewal}

The flexperts in our sample reported that expertise renewal starts with an "idea" or "opportunity to do something new." They described how they generated ideas by a range of activities and the usage of multiple sources (see Figure 1 for examples) resulting into a wide variety of ideas. In some cases, these ideas concerned the opportunity of acquiring high-level performance in an adjacent or new area of expertise. All flexperts identified opportunities to create a new field of expertise by making unique combinations among disciplines. For example, Int. 10 saw an opportunity to combine her expertise in the fashion industry with her ICT expertise to develop a new expertise area on "fashionable technology" during one of her expertise renewal episodes. Other flexperts described the opportunity of building upon an upcoming field of expertise. For example, one HRD flexpert (Int. 1) spotted the opportunity to acquire and materialize an upcoming expertise area, that is, early career crises, in the context of a growing demand for career support among young workers. In a subsequent renewal episode in her career, she noticed that "new ways of working" was another upcoming topic in the HRD field. She developed and implemented a method for organizations on new ways of working, and became a well-known expert on this new topic. Flexperts also identified opportunities to apply one's given expertise to a new environment, such as Int. 7 who spotted the opportunity to apply his specific medical expertise to a new patient group. Six flexperts were triggered by what they called "lacunas" regarding, for example, processes, customer insights, or systems. These lacunas could be a source for generating ideas for a 


\section{First-Order Codes*}

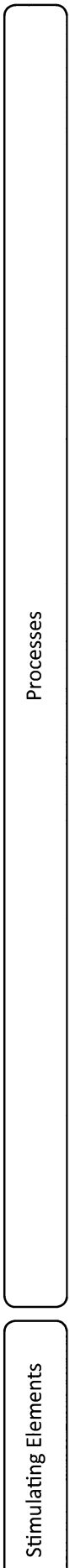

Activities by which flexperts generated ideas and identified opportunities to renew (e.g., "making new combinations", "brainstorming",

"philosophizing", encounters with "open minded people") and sources used (e.g., "trends" in fields of expertise, technological developments, "customer needs", "lacunas").

Reasons why a focus was needed (e.g., "right moment to focus"

"need to choose") and selection criteria relevant for individual

(e.g., "meaningfulness", "mission”, "impact”, fit with skills, knowledge,

or interest) and fit with the context of application

(e.g., "feasibility", fit customer needs, "go from leader").

(yet)"), general strategies for testing (e.g., "experimenting",

"piloting", "prototyping", "just doing"), and approaches (alone / others, part of formal / informal process).

Ways to acquire new knowledge and skills (e.g., "attending conferences", "training", types of self-study, "coaching", reflections upon testing outcomes) and expressions of awareness to what extent own knowledge, skills and performance are sufficient.

Ways to claim an idea or new area of expertise (e.g., "to be the first", "telling the outside world you are the expert") and ways of broadcasting this new expertise ("publishing every new insight", "authentic way") and channels used (e.g., TV, radio, social media, theatre, conferences) and experiences (e.g., "fear", "uncertainty", "discomfort" about communicating). +

Ways to create networks of ambassadors (e.g. "drinking lots of coffee" and "planting seeds"(Dutch expressions for creating buy-in), "making others enthusiastic", "building trust"), type of connections made (e.g., with individual people, between people) and type of ambassador (providing expertise, embedding in line-activities).

Creating financial space (e.g., available money, doing things for free), time (e.g., "free time", "no time restrictions"), taking freedom in decision making (e.g., "free role", "bypassing processes"), distance (e.g., "isolation", "stepping out").

"Finalizing" a product (e.g., "thorough testing" or "thorough analysis", work out all details, "building"). +

"Incorporating" products into existing or new processes and systems and "handover" to people with line responsibility.

Stimulating contextual conditions for renewal that were either a given or an outcome of their own activities: having space (see creating space for categories), having a network of people or being part of a "good" team (e.g., "open minded", multidisciplinary, "true experts", "supportive leader", "people who can execute") and reputation (e.g., "expert reputation", "high ranked job title", positive reputation).

Ways how flexperts expressed "who they are" characterizing how they generally behave or approach things (e.g., "having a mission", "striving for uniqueness", locus of control is self, "willingness to take risk", "liking challenge or action", "openness", "being ambitious", "perseverance", "organization sensitivity").

\section{Theoretical Categories Aggregated}

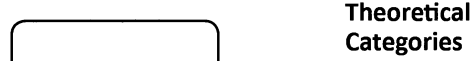

* All data were derived

from interviews and

the member validation.

The + indicates that

supplementary data

had been consulted.
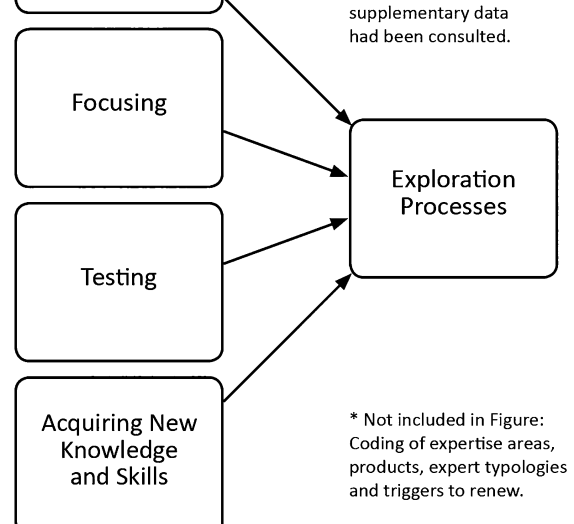

and triggers to renew.

Words or sentences

between double brackets
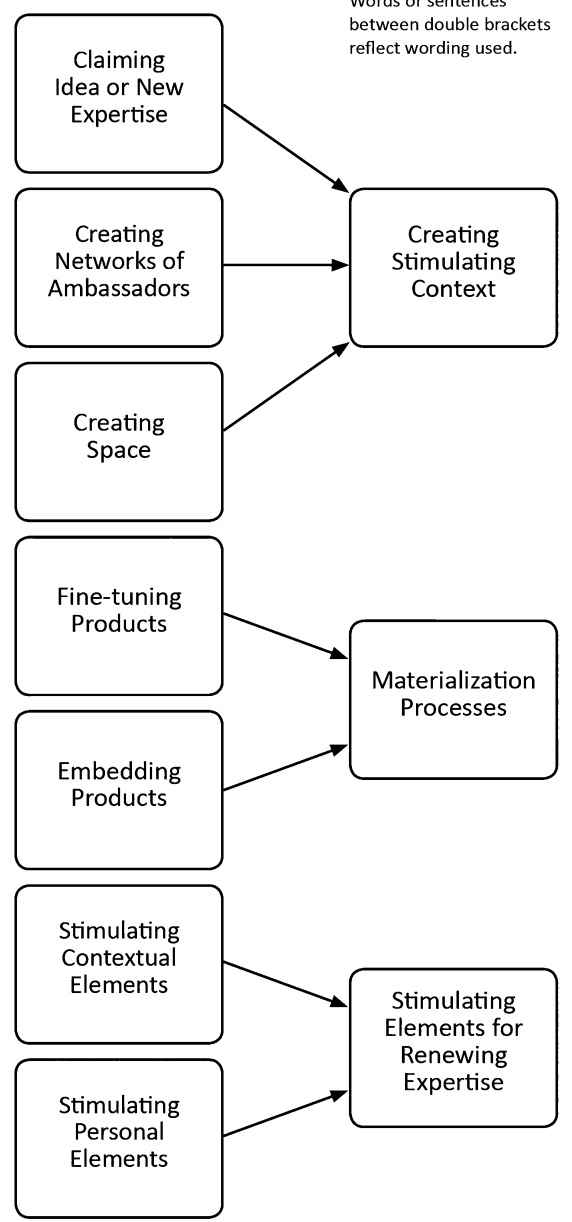

FIGURE 1 Overview of data structure 
product or process innovation. In other words, the flexperts had to learn a new area of expertise, being a fortunate side effect of this innovation. During the interviews and member validation, the flexperts reported that they were rather inclined to approach these lacunas as an opportunity for renewal, whereas others tend to perceive them as a problem or hindrance. Some flexperts described the process of generating ideas as a relatively effortless activity that could happen spontaneously, during work or private activities, as illustrated by Int. 2: "Good ideas are not steered by a date or time." In addition, the flexperts appeared to generate ideas either as a solitary act or as a result of being inspired by others, specifically "open-minded people" from multiple disciplines.

\subsection{Focusing: Selecting an idea out of the many ideas}

There appeared to be a kind of momentum to focus on either one or on a limited number of ideas, including opportunities to develop or materialize a new area of expertise. For example, Int. 10 described this type of situation as follows: "You have to stop whatever you are doing to seize an opportunity once it presents itself." A number of flexperts verbalized an intuitive feeling that a certain idea was potentially a good one. To take a well-considered decision whether an idea required further exploration, or whether it rather should be abandoned, all flexperts did multiple checks. We identified categories of personal and contextual checks that were used to evaluate an idea.

We clustered codes as personal checks in case the flexperts evaluated whether an idea could create outcomes in line with a number of personal characteristics or with their own needs. All but one flexpert checked whether an idea was expected to have meaningful outcomes in line with their personal mission, which was used as an overall guide in their career. For example, one ICT flexpert (Int. 10) explained that any decision on whether to start learning or doing new things was steered by her mission: "All the time going back to the mission: What is the mission? Does it fit and if not, ..., then don't do it ... For example ... our mission is to empower women through technology, that is what we stand for, thus for very specific women, and not for girls." In addition to checking the fit with one's personal mission, it was also important for the flexperts to be passionate about the idea, and to have relevant knowledge and skills. Others also checked whether they could have "impact" with the idea (Int. 3; 4; 8; 9; 10), or "be the first with an idea" stemming from a personal driver to be unique or different from others (Int. 1; 4; 5; 7; 9). The second category of checks concerned the fit with the context of application, relating to the environment and constituency, as explained in the introduction section. Depending upon the context, this has to do with, for example, the evaluation of whether the idea could potentially fulfill the customers' needs, or whether it seemed feasible to realize. Half of the participating flexperts specifically reported the importance of a "go" from their line manager to be a stimulating contextual factor, as illustrated by the following quote of Int. 6: "My direct supervisor [name] ... I encountered him frequently about, hey is this nice?, and he always said, yes, go on. Thus I started ... just doing." Being the first to come up with a certain idea was also a reason to select it. For example, one medical flexpert (Int. 7) noticed multiple times in his career that he could be ahead of others by developing a new area of expertise, for example described as: "An area ... nobody knows of ... meaning you are the first ... makes people interested, makes me to be invited everywhere."

The personal and contextual checks that have been outlined here were applied without a specific rank order. For example, the business management flexpert (Int. 3) described why he decided to focus on developing a new assessment tool: "Yes, because it is actually what ... I can, what I want, and what the market demands, these are the three ... things that come together." All in all, the flexperts focused on an idea because of its anticipated positive outcomes for both themselves and their stakeholders. Depending upon the specific expertise area or environment in which they were operating, these stakeholders could be customers, users, peers, or broader entities such as an organization as a whole or "the society." The expectations regarding positive outcomes justified themselves and others to spend time and money to (further) explore a certain idea. Some flexperts indicated that immediate action or testing was needed after a decision to focus on a certain idea to be "the first," summarized by Int. 9 as: "I spotted an opportunity and acted upon it." 


\subsection{Testing: Getting a better understanding of what the idea is about}

Flexperts reported multiple reasons for testing their idea. For example, one ICT flexpert (Int. 8) explained why he introduced an idea testing approach: "Now we know actually ... this is ... gold or this is nothing." Int. 10 explained that he was testing his ideas to get feedback on how well they were resonating with his audience, as explained in the following text excerpt: "If someone does not favor the idea than I have not explained it well enough, ... I must return to the drawing board to make the idea more clear." All flexperts mentioned that they tested their idea with the help of others, such as colleagues, relatives, and friends, whom they perceived as "open-minded people." Flexperts described specific strategies for testing their idea, which they described in wordings such as "experimenting," "prototyping," or "running a pilot." Six flexperts also frequently referred to this testing as "just doing." Moreover, the participating flexperts also gave examples of carrying out "thought experiments" by which they visualized and thought through an idea. The information resulting from testing activities was sometimes used to come up with the decision to focus on one of the flexpert's ideas, that is, the process of focusing as we described before. In addition, testing sometimes generated new ideas for the development of expertise in an adjacent or new domain.

\subsection{Acquiring new knowledge and skills: Becoming confident}

By acquiring new knowledge and skills, flexperts could enrich an idea resulting into a sound knowledge foundation for it, and enabling them to learn how to do things. This together gave flexperts a growing feeling of confidence to be an expert on the new topic. Even though flexperts voiced to continuously develop themselves in their broad field of expertise, they specifically delved deeper into topics during the exploration of a new field of expertise. They reported to have acquired new knowledge and skills by, for example, evaluating the outcomes of testing, extensive reading, consulting experts, attending conferences, joining training, interviewing, and observing. For example, Int. 1 described how she spends an extensive amount of hours on self-study by reading scientific articles on new ways of working, following experts in this field on social media, and reflecting on the effectiveness of methods that she had been trying out. In this way, she internalized peers' expertise supplemented with her own insights. She summarized this as follows: "Then it also became an expertise of myself." Int. 4 described the outcome of this process as "A cloud of knowledge that was expanding." Flexperts also recognized that some expertise areas were too deviant or dissimilar from their own one to cope independently with closing the accompanying knowledge and skills gap. This was illustrated by the following quote of one medical expert (Int. 9): "Don't try to be the expert in an area you are not." In that case, they attracted other experts (see the section Creating Networks of Ambassadors for more details).

\subsection{Creating a stimulating context}

The flexperts described how they were actively influencing their context, relating to elements of their expertise environment and constituency, aimed at stimulating both the (further) exploration of their idea, or the materialization of their expertise by means of fine-tuning and embedding a variety of products (see later on in this section). They all described three processes by which they created a (more) stimulating context where needed: claiming the idea, creating networks of ambassadors, and creating space. During the interviews and member validation, some flexperts mentioned that they differed from others by perceiving their context as something they could potentially influence, and as such applied the following three processes.

\subsection{1 | Claiming an idea or new expertise: Broadcasting to be the expert}

Along iterations of testing an idea and acquiring new expertise, all flexperts reached a point where they felt a need to claim their enriched idea or to associate their name with an emerging area of expertise given the insights gained. Besides, all flexperts communicated their idea or new area of expertise to inspire, inform, and make others familiar with it, and as such built their reputation or labelling as an expert on the new topic. More specifically, all flexperts claimed their selected idea by broadly communicating it as a new concept, vision, insight, product, approach, or new 
area of expertise, even though it was still in an explorative stage. Three flexperts purposively used a unique name for the new expertise area or gave themselves a special expert label. For example, one HRD flexpert (Int. 1) explained why she gave a special label to her growing expertise on "early career crisis": "I know a lot about it, I have done much with it, but you only will be seen if it gets a name." Seven flexperts reported a specific strategy: claiming a topic or new area of expertise by telling "to be the first." This claiming happened in organizations, among communities of peers, and in the public media. During the member validation, two ICT flexperts (Int. 4; 8) pointed out the necessity of the "right timing" for broadcasting, as people need to be "receptive to new ideas."

Flexperts claimed "ownership" of a new field before their newly obtained expertise was fully developed. Int. 1, 6, 8 , and 9 reported fear, uncertainty, or discomfort to communicate about their new expertise while not having sufficient expertise yet. This feeling is due to the fact that the audience expects an expert to be knowledgeable. HRD flexpert Int. 1 explained how she coped with this: "In the beginning you feel ill at ease because you are of course totally nothing, so the reflex is to keep up appearances." After an initial claim, it was a fruitful strategy to publish or broadcast every new insight or evidence that was found to further enhance their expert reputation. Figure 1 shows the multiple channels that were used for this broadcasting. By repeatedly telling the outside world you are the expert, it became a kind of self-fulfilling prophecy, illustrated by one medical expert (Int. 9) as: "By the act of being the expert, I became the expert."

\subsection{2 | Creating networks of ambassadors: Stimulating exploration and materialization}

The flexperts aimed to create networks of ambassadors to enable access to expertise and resources in favor of their intended renewal process, as reflected in the quote one ICT flexpert (Int. 10): "You need enthusiastic and interested people. You cannot handle it on your own ... I strongly belief that you can become anything you want and that everything is possible and no is actually not an option, but it requires that you can't do it on your own. ... I ask immediately for help." Another ICT flexpert (Int. 4) explained the need for creating ambassadors among various departments within his organization as follows: "The larger you are making your network and the longer you have been working somewhere, the higher the chance that things go faster, because you are much more of a spider in a web ... Instead of spinning a couple of strings, you have spun a thousand of these."

Flexperts described ambassadors as those people who were actively supporting their claim of a new area of expertise or the launch of an idea, either inside or outside an organization. Two types of ambassadors emerged from the interview data. The first type were experts with the required complementary or in-depth expertise who contributed to testing a preliminary idea and/or fine-tuning it into a product. The second type of ambassadors were line managers or colleagues with complementary planning or coordination skills, who helped to embed the new knowledge, skills, and products in regular processes and systems. If needed, they also helped in creating the required space (see the next paragraph for more details). The flexperts created networks of ambassadors as a side effect of involving them in the previously described processes of claiming and testing, and by involving them in the fine-tuning and embedding of products as we will describe further on. Flexperts also reported actions that were specifically targeted at creating ambassadors. They typically conducted these actions in bilateral settings, and actively built trust and expanded their network by making connections with and between people who should advocate or support their idea, new product, or new area of expertise. Flexperts purposively stimulated this process by using their expert reputation, their positive performance evaluation within the organization, or a high-ranked job title to gain easy access to people who could be their ambassador. If needed, these ambassadors could help the flexperts in creating "space" for renewal.

\subsection{3 | Creating space: Having the required room to explore}

All flexperts voiced examples of why they needed "space." They described space as a context that specifically provided them room to (further) explore an idea or a new area of expertise, as it helped them with generating new ideas, testing these, and deliberately studying. Space stimulated these processes as it provided, as reported by Int. 8, for 
example: "Freedom to take decisions." Int. 7 verbalized it as: "It allowed me to continue," and for Int. 4 "It helped to keep the energy." One HRD expert (Int. 5) described how "space" helped her to explore the opportunity of developing a new area of expertise. She explained how she frequently had created space throughout her career to make unique combinations of her expertise in arts, pedagogics, and business management. She described the function of space as something that people need to "reinvent themselves": "It opens up possibilities for individuals to become intrinsically motivated to define for themselves what to learn, how to deal with change, and, ultimately, how to reinvent themselves within the safety of the space."

Flexperts voiced examples of four different kinds of "space" that they either created themselves or that were perceived as stimulating elements that were provided by other parties: the possibility to circumvent existing processes or regulations, financial space, time, and distance. Eight flexperts bypassed existing processes that they perceived as a barrier, as described by one ICT flexpert (Int. 8) who created a position for himself akin to the "sweeper position" in football: "Now I do not need to ask anyone for permission, thus when I have an idea today, I can do it tomorrow." In a different way, Int. 3 and Int. 4 circumvented barriers by starting their own firm in combination with being employed. Int. 3 also commenced to work with start-ups to have more freedom to act. Six flexperts created financial space, for example by investing their own money (Int. 3; 5), doing work for free (Int. 1; 10), or by finding funds (Int. 2; 7). Int. 1, 5, 6, and 10 organized the time to do the things they wanted to do. Int. 1, 5, 6, and 9 isolated themselves for a longer period of time for an in-depth elaboration on the new topic.

\section{6 | Fine-tuning products}

The interviews and supplementary data showed that flexperts developed a variety of products by which they made their initial idea and new area of expertise accessible and useful for multiple stakeholders, both inside and outside an organization. For example, they developed ICT tools, summaries of their understanding (e.g., scientific articles, popular scientific books, and blogs), learning tools (e.g., eLearning, lectures, theater show, assessments, and coaching), methods (e.g., medical treatment, ICT selection process), or policies. One medical flexpert (Int. 9) explained that the development of products was a necessity to keep on being an expert: "... you have to produce, because it is a temporary status. You are an expert and ... people ascribe you this status on the basis of the knowledge and the materialization of your skills, but if you do not follow up on this ... than it breaks off. Your expert role will vanish." The development of usable products involved a process of fine-tuning. Some flexperts involved what they called "true experts" or "craftsman" for this process of fine-tuning given their in-depth expertise on a specific topic and/or their stronger focus on details. For example, one medical flexpert (Int. 7) involved a statistician who did a more thorough analysis to standardize a treatment. Similarly, one ICT flexpert (Int. 8) attracted another ICT specialist for systematic testing by which he made the product suitable for a customer launch.

\section{7 | Embedding products}

In parallel to this fine-tuning process, flexperts made sure that their products were integrated into existing processes and systems. Many flexperts preferred to handover this process of embedding, as well as the aforementioned process of fine-tuning, as reflected in the quote of Int. 8: "I never finish anything, that is a bad habit, but also a good habit, thus I reach $60,70 \%$ and then hand it over to ... people with line responsibility. Then I got rid of it and it allows me to do something new." In this process he considered the following: "How can I make sure that we build up something, which doesn't' break down .. if I withdraw." Flexperts reported losing interest or getting bored during this process of embedding and the aforementioned process of fine-tuning and started looking for "something new." They had these experiences because their work had become more routine, lowering the opportunities to learn something new, as illustrated by the following quote of Int. 9: "Look, in the beginning you are anxious and you want to do it right, but now I do not have that anymore ... it became a skill ... and this is a point where I think ... this is not attractive." As a result, flexperts were not much inclined to report extensively about the details of fine-tuning and 
embedding. Handing over the work to others, during this stage of materializing their expertise, often resulted into more openness for new opportunities, which could lead to the generation of ideas as a basis for a new expertise renewal episode.

\subsection{Toward a conceptual model of expertise renewal}

Based on this empirical work, we have developed a conceptual Model of Expertise Renewal visualized in Figure 2. It summarizes the previously described key processes, and explains how each process can be interconnected during an expertise renewal episode in a flexpert's career. We have distinguished three main process cycles: an exploration cycle, a cycle in which a stimulating context is created, and a materialization cycle.

An expertise renewal episode usually starts with generating ideas, including ideas for developing adjacent or new areas of expertise. It can set in motion a cycle of exploring a new expertise domain in which flexperts perform iterations of testing the value that the idea could have for others, and acquiring new knowledge and skills to enrich the preliminary idea. Sometimes these two processes generate new ideas in return. During the exploration cycle, flexperts make a wellconsidered decision by focusing on one or a limited set of ideas, often after some iterations of testing and acquiring new knowledge and skills. To do this, they weigh up both the potential of having beneficial outcomes for themselves as well as for relevant stakeholders. Having a focus can be a trigger to further test or enrich a certain idea.

If needed, flexperts start a cycle of processes by which they are creating a stimulating context in three different ways. Flexperts start claiming the idea or new expertise once they have sufficient testing data gathered and/or new knowledge and skills acquired. This claiming helps to build up an expert reputation on the new topic, herewith enhancing the possibilities of creating networks of ambassadors. This network can support exploration if it consists of people who can help with further testing, can provide additional knowledge and skills, or can help creating space, that is, the possibility to circumvent processes, gaining access to financial resources, having time available, and taking distance for further exploration. If the time is right, ambassadors can also contribute to the materialization of the newly acquired expertise.

The cycle of materializing ideas and new expertise typically starts after a number of exploration cycles. This is the stage in which it usually becomes clearer as to how a tested idea, enriched with new knowledge and skills, can be materialized after also having been able to create a (more) stimulating context. This materialization is realized by the development of tangible products for multiple stakeholders inside and outside an organization. It often requires the fine-tuning of products for which flexperts involve other (fl)experts among their network of ambassadors who have complementary or in-depth expertise on components of the desired output. Line managers from their network of

\section{Model of Expertise Renewal}

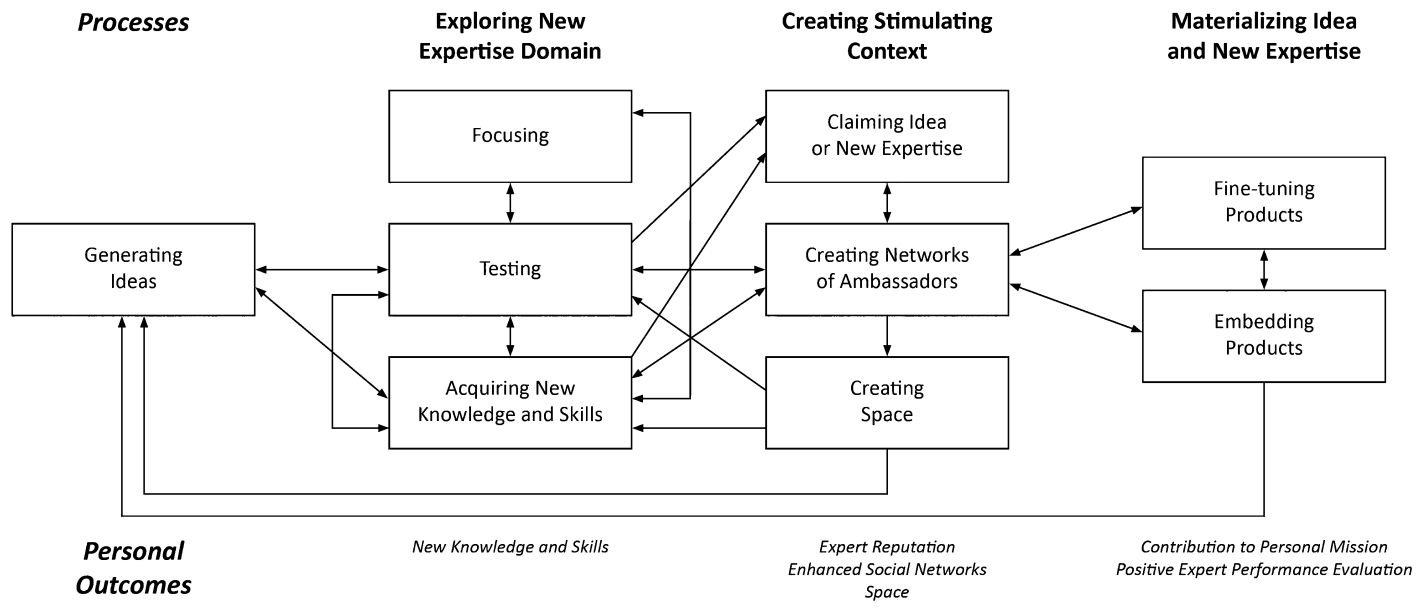

FIGURE 2 Conceptual model of expertise renewal 
ambassadors are usually involved in the process of embedding the new products in regular ways of working. Flexperts tend to hand over this fine-tuning and embedding to enable themselves to shift their attention to opportunities for developing new areas of expertise. This shift is often triggered if the work becomes more routine and when learning opportunities have grown thin. As flexperts are mobilizing ambassadors during the exploration cycles, they have relatively easy access to experts and line managers. Therefore, they may delegate the work of fine-tuning and embedding new products to start a new renewal episode in their career.

A sound expertise renewal episode can support flexperts in subsequent episodes in their career given the beneficial personal outcomes. First, exploration can generate new knowledge and skills that can enhance the flexpert's reputation, the quality of the products, and the generation of new ideas. Second, an expert reputation can help a flexpert in making people willing to become their ambassador. Third, an enhanced social network can help the flexpert during a future expertise renewal episode by providing expertise, mandate, and resources for both the exploration and the materialization of new ideas and expertise. Fourth, having space also helps in creating room to focus on a subsequent renewal episode. And finally, the implementation of new products based on a tested idea and enriched with new knowledge and skills can lead to a positive expert performance evaluation in line with one's personal mission.

To summarize, the Model of Expertise Renewal that we propose is iterative, meaning that an expertise renewal episode is characterized by recurrent sequences of two or more processes, such as for example the iterations of testing and acquiring new knowledge and skills. The model is multidirectional as flexperts move back and forth between exploration, creating a stimulating context for renewal, and materialization. The distinguished expertise renewal processes are executed in unique ways given the specific characteristics of the flexpert's expertise domain, environment, and audience, which requires a flexpert to adapt his or her behavior. Consequently, the sequence, frequency, and duration of processes is different between flexperts as well as across different episodes of a single flexpert, resulting into idiosyncratic expertise renewal paths by which a flexpert materializes new expertise for multiple stakeholders, both inside and outside the organization. As such, the model provides a framework for defining learning paths as we will further discuss in the final section of this article.

\section{4 | DISCUSSION}

\subsection{Contribution to the HRD scholarship}

With this contribution, we aim to shed more light on the richness and complexity of the processes by which flexperts develop and materialize new areas of expertise. By developing a conceptual Model of Expertise Renewal, we are able to extend the process models of Grenier and Kehrhahn (2008) and Ward et al. (2018). In line with Grenier and Kehrhahn's model of expertise redevelopment (2008), we have described the acquisition of new knowledge and skills as a shift from reliance on other resources toward a level of "transcendence" in which the possession of high-level domain-specific knowledge and skills is accompanied by a growing confidence, herewith providing a platform for starting new expertise renewal episodes. The alternation between the exploration and materialization cycles resembles the model of adaptive skill of Ward et al. (2018) to the extent that flexperts were both "making sense" of a preliminary idea to renew, and while "doing" things they were finding ways to materialize their idea or new area of expertise for multiple stakeholders.

Our model extends these two process models by the addition of processes and by their refinement. Firstly, we have added the processes by which flexperts generate and focus on ideas about how to deal with changing expertise demands, often described as opportunities for renewal. In the fields of entrepreneurship and intrapreneurship, many researchers were already captivated by the question of what makes people to perceive opportunities. Review studies of Baggen (2017), Brandstätter (2011), and George, Parida, Lahti, and Wincent (2016) described the positive effects of prior knowledge, social capital, and personality traits on opportunity recognition. Analogously, we could argue that the flexperts in this study recognized a wide variety of opportunities to develop new areas of expertise by having an extensive knowledge base and supportive social networks. Moreover, the abovementioned review studies showed that Big Five traits, in 
particular Openness, appeared to partly explain individual differences in opportunity recognition, which we assume to be characteristic for flexperts as well, given their explanations of how they were open for opportunities to deal with changes in their expertise territories. In line with Thunnissen et al. (2013), we posit that flexperts contribute to the sustainability of their careers by making a balanced decision to focus on those ideas that could create a value for multiple stakeholders in and outside an organization, as well as valuable outcomes for themselves.

Secondly, our model extends the aforementioned process models by the addition and refinement of processes by which flexperts interact with certain elements in their environment and with their audience, and by which they alter these elements if needed to stimulate the development and materialization of their newly gained expertise. Specifically, the flexperts seemed to organize their own resources by the process of creating ambassadors, and appeared to be able to circumvent barriers by the process of creating space. In this way, their activities resembled the so-called job-crafting strategies (e.g., Tims, Derks, \& Bakker, 2016) by which professionals influence elements of their environment to have a better personal fit with their job and to experience their work as more meaningful. To the best of our knowledge, earlier research on job-crafting strategies has not yet addressed the search for optimal strategies for (expert) reputation building by which an audience can be created or maintained among groups of stakeholders. Therefore, our contribution helps to close the knowledge gap on how the sustainability of professionals' careers can be enhanced (see also Van der Heijden \& De Vos, 2015).

\subsection{Limitations of this study and directions for future research}

This study has some limitations. First, although the flexperts operated in a variety of expertise areas and types of organizations, we found commonalities in their expertise renewal processes. However, given the limited number of flexperts interviewed, more empirical research is needed to determine the generalizability of our conclusions. This would also include to interview "negative cases" (Andersen et al., 2010; Boeije, 2010, p. 38) to verify eventual disproval of the provisional findings so far. In addition, follow-up research is needed to develop a generic (i.e., domainindependent) quantitative measurement instrument based on the newly developed conceptual model to test whether the described mechanisms are established in larger and more diverse samples.

Second, we should consider the possibility of a hindsight bias or internal attribution error (Kelley \& Michela, 1980). In particular, it could be that flexperts had a distorted recollection of their expertise renewal processes, and as such might have incorrectly attributed successes to their own efforts rather than perceiving it as an outcome of beneficial circumstances. Future research could make use of feedback from multiple sources, such as the flexpert's line managers and peers, to understand whether their performance is largely determined by the given context or facilitated by environmental elements and/or the audience, which was created by the flexpert him/herself.

Third, by only studying flexperts in the top end of the performance ratings, we should be cautious making statements about the extent to which they differ from those professionals who are less capable of renewing their expertise. Therefore, we suggest that further quantitative research explores the potential effects of personality characteristics on the flexpert's ability, varying in terms of excellence, to recognize opportunities for developing new expertise, and the exploration and materialization of these opportunities.

Fourth and finally, as we have only incorporated Dutch experts, it is worthwhile to cross validate our findings with a more culturally diverse flexpert population. As there are cultural differences in the way that people grant status to someone and to what extent people act as an individual or a group (Trompenaars \& Hampden-Turner, 1998; Yuan, Bazarova, Fulk, \& Zhang, 2013), we recommend to further examine cross-cultural differences in building up and maintaining flexpert reputation.

\subsection{Implications for the HRD practice}

Expertise is argued to be a core concept for the HRD practice, as much of the work concerns "unleashing expertise for the purpose of improving performance" (Swanson \& Holton, 2009, p. 252), and, therefore, we will conclude with practical recommendations for the HRD practice. Over the past few years, there has been an increased focus on how 
employees can take responsibility for their own career (Poell \& Van der Krogt, 2014; Van der Heijden \& De Vos, 2015). In this regard, Poell (2017, p. 14) called for more attention on how employees create their own learning paths, and how HRM and HRD managers, and other actors can influence professionals in having sustainable careers. A learning path refers to "a set of learning-relevant activities that are both coherent as a whole and meaningful to the employee" (Poell, 2017, p. 11), and can be described by the learning theme, learning activities, social context, learning facilities, and the learning motive. The conceptual Model of Expertise Renewal provides a framework for experts to create their own learning paths in situations wherein learning is required as a result of the shifting demands for their expertise. It shows that experts need to make a deliberate choice for selecting a learning theme, taking the needs of multiple stakeholders or actors into account as well as the fit with one's own learning motive or mission. Furthermore, it shows that in the light of a sound design of learning activities, experts have to involve and expand their social network to materialize the new expertise for both themselves and multiple stakeholders. For initiating these learning activities, they should also play an active role in arranging learning facilities.

To better understand which group of experts might require developmental support, a HRD professional could conduct an initial assessment of their level of expert performance, and in particular, of their level of "growth and flexibility" (Van der Heijden, 2000). Subsequently, a HRD professional could use the Model of Expertise Renewal to review, together with the expert and line manager, which processes the expert finds difficulty to deploy and/or which elements of the expert's environment or constituency may stimulate or hinder one or more processes. As such, the Model of Expertise Renewal can be used to identify where a certain process of an expert was enhanced or, in contrast, where opportunities for creating beneficial outcomes for stakeholders involved or for the expert's career have not been seized. A HRD professional could use these insights for the design of learning interventions in close collaboration with the experts and their line mangers (Poell \& Van der Krogt, 2014). These interventions could focus on how experts can be a strategic actor by creating their own learning paths and/or the development of abilities, which are required for specific expertise renewal processes. Given the notion that flexperts might differ from their less-flexible peers with regard to their perception of how they can influence their context, a HRD professional or line manager could specifically focus on making the latter ones more aware of the possibility to shape their social context and learning facilities, using insights on how job-crafting abilities can be developed (Tims, Bakker, \& Derks, 2012, p. 176). Thus, by stimulating experts to create their own learning paths and learning them how to create a stimulating context, HRD practitioners can support experts in dealing with changing expertise demands to safeguard the sustainability of their professional career.

\section{NOTES}

${ }^{1}$ See Appendix I of Van der Heijden's dissertation (1998) for an overview of definitions of experts and expertise.

${ }^{2}$ There was one exception to the 10-year rule in our final sample: one flexpert had 8 years of experience in an upcoming younger field of ICT.

${ }^{3}$ The template for Figure 1 has been derived from Pratt, Rockmann, and Kaufmann (2006).

\section{ORCID}

Lonneke S. Frie (D) https://orcid.org/0000-0002-5275-8935

\section{REFERENCES}

Alexander, P. A., Schallert, D. L., \& Hare, V. C. (1991). Coming to terms: How researchers in learning and literacy talk about knowledge. Review of Educational Research, 61(3), 315-344. https://doi.org/10.3102/00346543061003315

Andersen, D. L., Luna-Reyes, L. F., Diker, V. G., Black, L., Rich, E., \& Andersen, D. F. (2010). The disconfirmatory interview as a strategy for the assessment of system dynamics models. System Dynamics Review, 28(3), 255-275. https://doi.org/10. 1002/sdr.1479

Anderson, V. (2017). Criteria for evaluating qualitative research. Human Resource Development Quarterly, 28(2), $125-133$. https://doi.org/10.1002/hrdq.21282 
Arbesman, S. (2012). The half-life of facts: Why everything we know has an expiration date. London, England: Penguin Putnam.

Baggen, Y. (2017). Opportunity identification competence. Explaining individual and exploring team opportunity identification by employees (doctoral dissertation). University of Wageningen. doi:https://doi.org/10.18174/393037

Birney, D. P., Beckmann, J. F., \& Wood, R. E. (2012). Precursors to the development of flexible expertise: Metacognitive selfevaluations as antecedents and consequences in adult learning. Learning and Individual Differences, 22, 563-574. https:// doi.org/10.1016/j.lindif.2012.07.001

Boeije, H. (2010). Analysis in qualitative research. Los Angeles, CA: Sage.

Bohle Carbonell, K., Könings, K. D., Segers, M., \& Van Merriënboer, J. J. G. (2016). Measuring adaptive expertise: Development and validation of an instrument. European Journal of Work and Organizational Psychology, 25, 167-180. https://doi. org/10.1080/1359432X.2015.1036858

Bohle Carbonell, K., Stalmeier, R. E., Könings, K. D., Segers, M., \& Van Merriënboer, J. J. G. (2014). How experts deal with novel situations: A review of adaptive expertise. Educational Research Review, 12, 14-29. https://doi.org/10.1016/j. edurev.2014.03.001

Brandstätter, H. (2011). Personality aspects of entrepreneurship: A look at five meta-analyses. Personality and Individual Differences, 51, 222-230. https://doi.org/10.1016/j.paid.2010.07.007

CBS (2015). Lack of important new skills or know how among nearly a quarter of Dutch employees. Retrieved from https:// www.cbs.nl/en-gb/news/2015/21/lack-of-important-new-skills-or-know-how-among-nearly-a-quarter-of-dutchemployees

Charmaz, K. (2014). Constructing grounded theory: A practical guide through qualitative analysis. London, England: Sage.

Chi, M. T. H., Glaser, R., \& Farr, M. J. (Eds.). (1988). The Nature of expertise. Hillsdale, MI: Lawrence Erlbaum.

De Vos, A., \& Van der Heijden, B. I. J. M. (2017). Current thinking on contemporary careers: The key roles of sustainable HRM and sustainability of careers. Current Opinions in Environmental Sustainability, 28, 41-45. https://doi.org/10.1016/j. cosust.2017.07.003

Ericsson, K. A. (2006). The influence of experience and deliberate practice on the development of superior expert performance. In K. A. Ericsson, N. Charness, P. J. Feltovich, \& R. R. Hoffman (Eds.), The Cambridge handbook of expertise and expert performance (pp. 683-703). Cambridge, England: Cambridge University.

Ericsson, K. A. (2014). Adaptive expertise and cognitive readiness: A perspective from the expert-performance approach. In H. O'Neil, R. Perez, \& E. Baker (Eds.), Teaching and measuring cognitive readiness (pp. 179-197). Boston, MA: Springer.

Ericsson, K. A., Krampe, R. T., \& Tesch-Römer, C. (1993). The role of deliberate practice in the acquisition of expert performance. Psychological Review, 100(3), 363-406. https://doi.org/10.1037/0033-295X.100.3.363

Feltovich, P. J., Prietula, M. J., \& Ericsson, K. A. (2018). Studies of expertise from psychological perspectives: Historical foundations and recurrent themes. In K. A. Ericsson, R. R. Hoffman, A. Kozbelt, \& A. M. Williams (Eds.), The Cambridge handbook of expertise and expert performance (2nd ed., pp. 59-83). Cambridge, England: Cambridge University.

George, N. M., Parida, V., Lahti, T., \& Wincent, J. (2016). A systematic literature review of entrepreneurial opportunity recognition: Insights on influencing factors. International Entrepreneur Management Journal, 12, 309-350. https://doi.org/10. 1007/s11365-014-0347-y

Germain, M., \& Tejeda, M. J. (2012). A preliminary exploration on the measurement of expertise: An initial development of a psychometric scale. Human Resource Development Quarterly, 23(2), 203-232. https://doi.org/10.1002/hrdq.21134

Grenier, R. S., \& Kehrhahn, M. (2008). Towards an integrated model of expertise redevelopment and its implications for HRD. Human Resource Development Review, 7(2), 198-217. https://doi.org/10.1177/1534484308316653

Hatano, G., \& Inagaki, K. (1986). Two courses of expertise. In H. Stevenson, H. Azuma, \& K. Hakuta (Eds.), Child development and education in Japan (pp. 262-272). San Francisco, CA: Freeman.

Hatano, G., \& Oura, Y. (2003). Commentary: Reconceptualizing school learning using insight from expertise research. Educational Researcher, 32(8), 26-29. https://doi.org/10.3102/0013189X032008026

Holtskog, H. (2017). Defining the characteristics of an expert in a social context through subjective evaluation. Journal of the Knowledge Economy, 8, 1014-1031. https://doi.org/10.1007/s13132-015-0312-1

Kelley, H. H., \& Michela, J. L. (1980). Attribution theory and research. Annual Review of Psychology, 31, 457-501. https://doi. org/10.1146/annurev.ps.31.020180.002325

Laloux, F. (2015). Reinventing organizations. Brussels, Belgium: Nelson Parker.

Levy, F., \& Murnane, R. J. (2004). The new division of labor. How computers are creating the next job market. New York, NY: Russell Sage.

Macnamara, B. N., Hambrick, D. Z., \& Oswald, F. L. (2014). Deliberate practice and performance in music, games, sports, education, and professions: A meta-analysis. Psychological Science, 25, 1608-1618. https://doi.org/10.1177/0956797614535810

Marand, A. D., \& Noe, R. A. (2017). Facilitating the development of expertise: An individual to organizational perspective. In K. G. Brown (Ed.), The Cambridge handbook of workplace training and employee development (pp. 38-74). Cambridge, UK: University Press.

McKinsey. (2017). Digitally-enabled automation and artificial intelligence: Shaping the future of work in Europe's digital front-runners. Retrieved from https://www.mckinsey.com/global-themes/europe/shaping-the-future-of-work-in-europes-ninedigital-front-runner-countries 
Mieg, H. A. (2006). Social and sociological factors in the development of expertise. In K. A. Ericsson, N. Charness, P. J. Feltovich, \& R. R. Hoffman (Eds.), The Cambridge handbook of expertise and expert performance (pp. 743-760). Cambridge, England: Cambridge University Press.

Murphy, C., Klotz, A. C., \& Kreiner, G. E. (2017). Blue skies and black boxes: The promise (and practice) of grounded theory in human resource management research. Human Resource Management Review, 27, 291-305. https://doi.org/10.1016/ j.hrmr.2016.08.006

Neimeyer, G. J., Taylor, J. M., Rozensky, R. H., \& Cox, D. R. (2014). The diminishing durability of knowledge in professional psychology: A second look at specializations. Professional Psychology: Research and Practice, 45(2), 92-98. https://doi. org/10.1037/a0036176

OECD. (2009). $21^{\text {st }}$ century skills and competences for new millennium learning in OECD countries (EDU Working Paper No. 41). Retrieved from http://www.oecd.org/officialdocuments/publicdisplaydocumentpdf/?cote=EDU/WKP(2009) 20\&doclanguage $=$ en

Oldham, G. R., \& Hackman, J. R. (2010). Not what it was and not what it will be: The future of job design research. Journal of Organizational Behavior, 31, 463-479. https://doi.org/10.1002/job.678

Poell, R. F. (2017). Time to 'flip' the training transfer tradition: Employees create learning paths strategically. Human Resource Development Quarterly, 28(1), 9-15. https://doi.org/10.1002/hrdq.21279

Poell, R. F., \& Van der Krogt, F. J. (2014). The role of human resource development in organizational change: Professional development strategies of employees, managers and HRD practitioners. In S. Billett, C. Hanteis, \& H. Grub (Eds.), International handbook of research in professional and practice-based learning (pp. 1043-1070). Dordrecht, The Netherlands: Springer.

Pratt, M. G., Rockmann, K. W., \& Kaufmann, J. B. (2006). Constructing professional identity: The role of work and identity learning cycles in the customization of identity among medical residents. Academy of Management Journal, 49, $235-262$. https://doi.org/10.5465/amj.2006.20786060

Simon, H. A., \& Chase, W. G. (1973). Skill in chess. American Scientists, 61, 175-188.

Sosniak, L. A. (2006). Retrospective interviews in the study of expertise and expert performance. In K. A. Ericsson, N. Charness, P. J. Feltovich, \& R. R. Hoffman (Eds.), The Cambridge handbook of expertise and expert performance (pp. 287-302). Cambridge, England: Cambridge University.

Strauss, A. L., \& Corbin, J. (2007). Basics of qualitative research. Techniques and procedures for developing a grounded theory (3rd ed.). Thousand Oaks, CA: Sage.

Susskind, R. E., \& Susskind, D. (2015). The future of the professions: How technology will transform the work of human experts. New York, NY: Oxford University.

Swanson, R., \& Holton, E. (2009). Foundations of human resource development (2nd ed.). San Francisco, CA: Berrett-Koehler.

Thunnissen, P., Boselie, P., \& Fruytier, B. (2013). Talent management and the relevance of context: Towards a pluralistic approach. Human Resource Management Review, 23(4), 326-336. https://doi.org/10.1016/j.hrmr.2013.05.004

Tims, M., Bakker, A. B., \& Derks, D. (2012). Development and validation of the job crafting scale. Journal of Vocational Behavior, 80, 173-186. https://doi.org/10.1016/j.jvb.2011.05.009

Tims, M., Derks, D., \& Bakker, A. B. (2016). Job crafting and its relationship with person-job fit and meaningfulness: A threewave study. Journal of Vocational Behavior, 92, 44-53. https://doi.org/10.1016/j.jvb.2015.11.007

Trompenaars, F., \& Hampden-Turner, C. (1998). Riding the waves of culture: Understanding cultural diversity in global business (2nd. ed.). New York, NY: McGraw-Hill.

Van der Heijden, B. I. J. M. (1998). The measurement and development of professional expertise throughout the career: A retrospective study among higher level Dutch professionals. (Doctoral dissertation). Retrieved from http://www.ru.nl/library/ resources/radboud_repository/

Van der Heijden, B. I. J. M. (2000). The development and psychometric evaluation of a multi-dimensional measurement instrument of professional expertise. High Ability Studies, 11, 9-39. https://doi.org/10.1080/713669175

Van der Heijden, B. I. J. M. (2005). 'No one has ever promised you a rose garden'. On the shared responsibility and employability enhancing strategies throughout career. Inaugural address, Heerlen: Open University of The Netherlands. Assen, The Netherlands: Van Gorcum.

Van der Heijden, B. I. J. M., \& De Vos, A. (2015). Sustainable careers: introduction chapter. In B. I. J. M. Van der Heijden \& A. De Vos (Eds.), Handbook of research on sustainable careers (pp. 1-19). Cheltenham, England: Edward Elgar.

Ward, P., Gore, J., Hutton, R., Conway, G. E., \& Hoffman, R. R. (2018). Adaptive skill as the condition sine qua non of expertise. Journal of Applied Memory and Cognition, 7, 35-50. https://doi.org/10.1016/j.jarmac.2018.01.009

Will-Zocholl, M. (2017). New topologies of work: Informatisation, virtualisation and globalisation in automotive engineering. In J. Flecker (Ed.), Space, place and global digital work (pp. 31-51). London, England: Palgrave Macmillan.

World Economic Forum. (2016). The future of jobs: The future of jobs and skills. Retrieved from http://reports.weforum.org/ future-of-jobs-2016/skills-stability/

World Employment Confederation. (2016). The future of work: White paper from the employment industry. Retrieved from http://www.wecglobal.org/fileadmin/templates/ciett/docs/WEC_-_The_Future_of_Work_-_What_role_for_the_ employment_industry.pdf 
Yuan, Y. C., Bazarova, N. N., Fulk, J., \& Zhang, Z. (2013). Recognition of expertise and perceived influence in intercultural collaboration: A study of mixed American and Chinese groups. Journal of Communication, 63, 476-497. https://doi.org/10. 1111/jcom.12026

\section{AUTHOR BIOGRAPHIES}

Lonneke S. Frie, MSc is a PhD student at The Hague University of Applied Sciences (THUAS) and the Radboud University, Institute for Management Research, Nijmegen, the Netherlands. At THUAS, she is senior lecturer and educational innovator at the HRM study program, and researcher at the research group Sustainable Talent Development. During her international career as senior HRD professional, she developed a special interest for expert development, intrapreneurship and sustainable careers.

Dr. Karin C. J. M. Potting is senior lecturer at the study program HRM, and researcher at the research group Sustainable Talent Development of The Hague University of Applied Sciences, the Netherlands. She has a multidisciplinary background in history, economics, HRM and HRD. She published HRM study books on International Talent Development, HR analytics and labor market trends. Her current research areas are: the impact of robotization on the employability of employees and decision making processes.

Dr. Ellen Sjoer is professor of Sustainable Talent Development at The Hague University of Applied Sciences, the Netherlands. Her research focus areas are: professional development/HRD, lifelong learning, and educational innovation. She has published books for the vocational practice of educational professionals, and has published, among others in the International Journal for Academic Development, European Journal of Teacher Education, Educational Research Review, and the European Journal of Engineering Education. She participates in various professional networks, and is a board member of the IACEE (International Association for Continuing Engineering Education).

Prof. Beatrice I. J. M. Van der Heijden, PhD is professor of Strategic HRM at the Radboud University, Institute for Management Research, Nijmegen, the Netherlands, and Head of the Department Strategic HRM. Moreover, she occupies a Chair in Strategic HRM at the Open University of the Netherlands, at Kingston University, London, UK, and at Hubei University, Wuhan, China. Her main research areas are: career development, employability, and aging at work. Van der Heijden is Associate Editor for the European Journal of Work and Organizational Psychology and co-Editor for the German Journal of Human Resource Management, and has published, among others in the European Journal of Work and Organizational Psychology, Journal of Vocational Behavior, HRM, Journal of Occupational and Organizational Psychology, and Career Development International. She is co-editor of the Handbook of Research on Sustainable Careers (EE Publishing).

Dr. Hubert P. L. M. Korzilius is associate professor of Research Methodology at the Institute for Management Research of the Radboud University, Nijmegen, the Netherlands. His current research interests are: research methodology, method development, cross-cultural management, dynamic decision making, system dynamics and group mental models. He has published books, book chapters and scientific journals, among others in the European Journal of Operational Research, Food Policy, Frontiers in Psychology, International Journal of Intercultural Relations, System Dynamics Review, and Systems Research and Behavioral Science.

How to cite this article: Frie LS, Potting KCJM, Sjoer E, Van der Heijden BIJM, Korzilius HPLM. How flexperts deal with changing expertise demands: A qualitative study into the processes of expertise renewal. Human Resource Development Quarterly. 2019;30:61-79. https://doi.org/10.1002/hrdq.21335 